\title{
Belgeo
}

Revue belge de géographie

\section{Le maraîchage : révélateur du dynamisme des campagnes sahélo-soudaniennes}

Market gardening, a pointer to vitality in the Sahelo-Sudanian rural area

\section{Stéphane Bastin et Audrey Fromageot}

\section{CpenEdition}

\section{Journals}

Édition électronique

URL : http://journals.openedition.org/belgeo/10106

DOI : 10.4000/belgeo.10106

ISSN : 2294-9135

Éditeur :

National Committee of Geography of Belgium, Société Royale Belge de Géographie

\section{Édition imprimée}

Date de publication : 31 décembre 2007

Pagination : 415-428

ISSN : 1377-2368

\section{Référence électronique}

Stéphane Bastin et Audrey Fromageot, «Le maraîchage : révélateur du dynamisme des campagnes sahélo-soudaniennes », Belgeo [En ligne], 4 | 2007, mis en ligne le 18 octobre 2013, consulté le 19 avri 2019. URL : http://journals.openedition.org/belgeo/10106 ; DOI : 10.4000/belgeo.10106

Ce document a été généré automatiquement le 19 avril 2019.

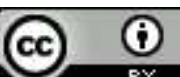

Belgeo est mis à disposition selon les termes de la licence Creative Commons Attribution 4.0 International. 


\title{
Le maraîchage : révélateur du dynamisme des campagnes sahélo- soudaniennes
}

\author{
Market gardening, a pointer to vitality in the Sahelo-Sudanian rural area
}

Stéphane Bastin et Audrey Fromageot

\section{Introduction}

1 En novembre 2004, les Nations unies avaient lancé un appel pour le Niger. Une invasion de criquets avait ravagé le pays. Une crise alimentaire était à prévoir. En mai dernier, alors que la sécheresse était venue aggraver la situation, l'ONU appelait de nouveau à l'aide.

Sans une action immédiate, le Niger était menacé de famine (Le Monde, 24 juillet 2005).

2 Ces lignes sont emblématiques du discours afro-pessimiste croissant dans les analyses produites sur l'espace africain depuis qu'au milieu des années 1980 une situation de crises enchevêtrées y a émergé. Selon ce discours, l'Afrique ne correspondrait plus qu'à une terre de misères - pauvreté, conflits, épidémies, désertification, famines - face auxquelles ses habitants seraient incapables de réagir de façon autonome (Courade, 2006 ; Dubresson \& Raison, 2003). La récente Négrologie du journaliste S. Smith fait ainsi l'oraison funèbre du continent africain dont la "mort" incomberait avant tout à des populations "se refusant à entrer dans la modernité autrement qu'en passager clandestin ou en consommateur vivant aux crochets du reste du monde" (Smith, 2003, p. 227 et 230). Très présent dans les discours médiatiques, l'afro-pessimisme s'immisce également - sous forme de réapparition pour certains $^{1}$ - dans d'autres disciplines comme l'histoire (Chrétien, 2006; CoqueryVidrovitch, 1997), mais aussi la géographie. Analysant le traitement de l'espace africain dans une dizaine d'études de géographie humaine des années 1990, G.A. Myers (2001) relève ainsi une tendance à privilégier la description symptomatique de la crise plutôt que la compréhension des dynamiques qui lui sont sous-jacentes ou associées. Selon l'auteur, de telles études en viennent ainsi à sous-estimer, voire à nier, l'existence du rôle 
actif que peuvent prendre les Africains pour lutter contre ces éléments de crise (Myers, 2001, p. 527).

3 Associé aux images télévisuelles dépréciatives et à la plaidoirie misérabiliste du secteur associatif, l'afro-pessimisme alimente donc les représentations d'une Afrique à l'agonie et dont le développement ne viendrait que d'opérations pilotées de l'extérieur. Pourtant, beaucoup de mutations en cours ne reflètent guère cette apparente léthargie. Ce sont, par exemple, les cas du redéploiement spontané des mobilités humaines et des réseaux commerciaux en faveur des anciennes routes du commerce transsaharien (Bensaad, 2002 ; Pliez, 2002 ; Grégoire, 1998), du développement de la métallurgie urbaine de récupération (Colomb \& Boumaza, 1994) ou encore de l'essor du vivrier marchand (Chaléard, 1996). Et bien que la diffusion du maraîchage dans les campagnes sahélo-soudaniennes participe pleinement à cet essor, peu d'attention a encore été portée sur ses mécanismes. Leur étude montre pourtant combien l'expansion de nouvelles cultures commerciales peut témoigner de capacités paysannes à surmonter un contexte de crise aux multiples facettes.

4 C'est ce que nous nous proposons de montrer à travers l'analyse conjointe du récent développement des cultures maraîchères dans les campagnes du Songhay nigérien et $d u$ Sénoufo ivoirien.

\section{Songhay nigérien et Sénoufo ivoirien}

\section{Les systèmes d'activité}

5 Le Songhay nigérien et le Sénoufo ivoirien sont situés dans la frange sahélo-soudanienne de l'Afrique occidentale (figures $1 \mathrm{a}$ et $1 \mathrm{~b}$ ). Cette frange est rythmée par l'alternance d'une saison humide (mai à octobre pour le Sénoufo; juin à septembre pour le Songhay) et d'une saison sèche.

6 La saison pluviale focalise la majeure partie du travail agricole. Au Songhay, il est dominé par les cultures de mil et de sorgho. Ces deux produits constituent les bases de l'alimentation familiale, tandis que la culture de riz pratiquée le long du fleuve Niger est essentiellement à finalité commerciale. A cette céréaliculture s'ajoutent quelques cultures individuelles d'appoint (haricot niébé, manioc, patate douce essentiellement) ainsi que celle du gombo (à la fois condimentaire et de rente). Au Sénoufo, ce sont le maïs (base de l'alimentation villageoise) et le coton (principale culture commerciale) qui constituent les deux grandes productions agricoles. Mais comme au Songhay, on peut y ajouter une série de cultures secondaires, certaines d'appoint (haricot, igname, riz pluvial, sorgho, arachide et gombo), d'autres essentiellement consommées lors des cérémonies villageoises (mil et riz pluvial inondé dans les bas-fonds). 

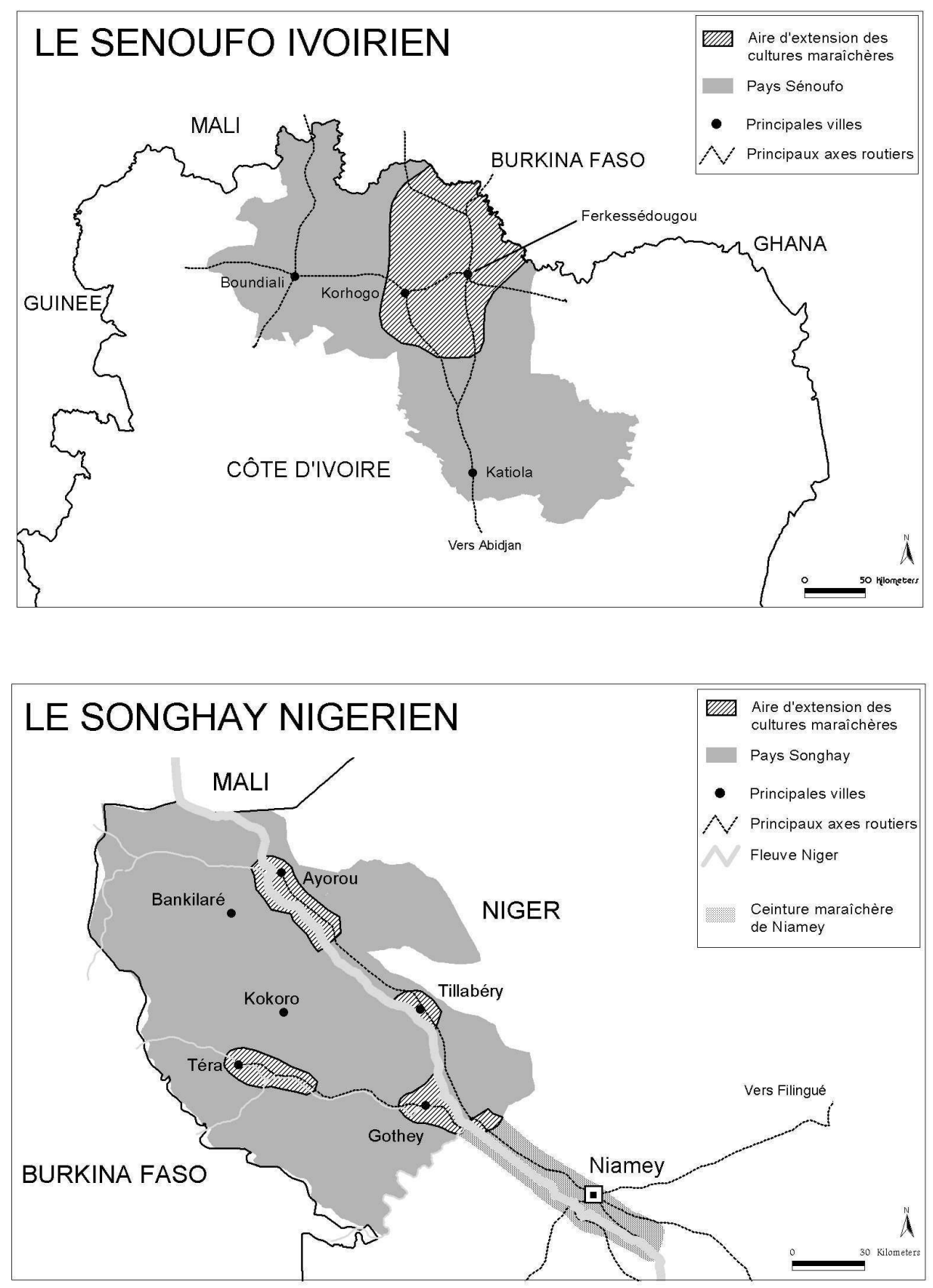

7 Si l'activité agricole se concentre pendant la saison des pluies, une campagne rizicole est, elle, pratiquée pendant la saison sèche sur les périmètres hydro-agricoles aménagés dans la portion songhay du Niger et par les femmes dans les bas-fonds humides des campagnes sénoufo. Mais là n'est pas la principale activité de saison sèche. Qu'ils soient du Songhay ou du Sénoufo, les hommes s'y consacrent plutôt à l'exode temporaire tandis que leurs femmes y entretiennent - par arrosage manuel ou en décrue - de petits potagers destinés à produire quelques légumes condimentaires (oignons, piments, courges, tomates, melons et plantes aromatiques). 
8 Les femmes et les hommes des deux espaces disposent enfin d'un petit élevage domestique (bovin, caprin et ovin essentiellement) qui constitue un capital traditionnellement réservé au financement des fêtes religieuses (baptêmes, mariages...) ou pour faire face aux aléas (mauvaise récolte, soins de santé...) ${ }^{2}$.

9 Agriculture pluviale (ainsi que riziculture irriguée chez les Songhay du fleuve ou inondée chez les Sénoufo), exode de saison sèche et élevage sont donc les trois grandes activités permettant classiquement aux paysanneries songhay et sénoufo d'assurer leur subsistance. La pratique du maraîchage est récemment venue s'ajouter à ce trio.

\section{Le maraîchage}

10 Le maraîchage, ou culture maraîchère, se distingue de la culture potagère en ce sens qu'il consiste à produire des légumes à des fins commerciales. Le maraîchage est essentiellement pratiqué pour approvisionner les marchés d'Abidjan (pour le Sénoufo) et de Niamey (pour le Songhay), même si les villes secondaires (comme Tillabéry, Téra ou Dori pour le Songhay) constituent un débouché de plus en plus fréquent. Les cultures maraîchères prennent place durant la saison sèche dans les bas-fonds, à proximité des mares, à l'intérieur du lit des cours d'eau intermittents, sur les rives et îles du Niger (Songhay) ainsi qu'en bordure des périmètres rizicoles (Songhay) et des petits barrages hydro-pastoraux (Sénoufo). Tous ces sites fournissent l'eau nécessaire à l'arrosage des légumes parmi lesquels l'oignon et le piment sont dominants ainsi que la courge au Niger et la tomate en Côte d'Ivoire. Cet arrosage s'effectue le plus souvent manuellement à l'aide de seaux, d'arrosoirs, de calebasses ou de canaris.

11 Le maraîchage ne s'est véritablement généralisé dans les campagnes songhay et sénoufo que durant les années 1990 même s'il était déjà pratiqué de manière très localisée auparavant: à proximité des centres régionaux de Korhogo dans le nord de la Côte d'Ivoire (ancienne spécialisation dans la production de tomates), de Gothey et Sakoira au Niger.

12 Les chiffres disponibles pour le Songhay ${ }^{3}$ montrent qu'après avoir stagné à environ 10000 tonnes produites par an, les cultures de légumes voient leur production passer à 45000 tonnes durant la saison 1987/88, puis à 80000 tonnes au milieu des années 1990 pour enfin atteindre 115000 tonnes en 1999. Cet accroissement continu est le résultat de l'augmentation soutenue du nombre d'exploitants et de l'extension parallèle des superficies cultivées (qui passent de 1300 ha cultivés en 1987 à 11000 ha en 1999). Bien que de telles statistiques n'existent pas pour le Sénoufo, il est possible d'y mesurer le phénomène de diffusion des cultures maraîchères en consultant l'évolution du nombre de producteurs d'oignons, encadrés par les agents de la CIDVi $^{4}$ puis de l'ANADER ${ }^{5}$, de la Région Nord6 (Fromageot, 1996). Selon ces agences, le nombre d'exploitants n'a réellement commencé à augmenter qu'à partir de 1991 : de 1200 en 1990, il est passé à 2500 en 1991 puis à 8000 dans la seconde moitié des années 1990.

Bien que ces chiffres soient à envisager avec prudence (étant donné le manque d'informations sur les méthodes de collecte), ils n'en demeurent pas moins les indicateurs d'une tendance - révélée par nos enquêtes de terrain - à l'expansion des cultures maraîchères des Songhay et Sénoufo dans le courant des années 1990. Comment interpréter cette expansion? A-t-elle été impulsée de l'extérieur ou correspond-t-elle à une dynamique endogène de développement? 


\section{La diffusion du maraîchage : un phénomène parachute de l'extérieur?}

14 Cette expansion se réalise à un moment où les politiques de promotion des cultures maraîchères qui avaient été engagées au début des années 1980 par les états nigérien et ivoirien arrivent à leur terme.

Entre 1982 et 1987, le Niger s'était en effet lancé dans une vaste entreprise de promotion des "cultures de contre-saison" (dont un programme d'urgence durant la saison 1984/1985) tandis qu'en 1984, le Nord de la Côte d'Ivoire se dotait, pour 10 ans, d'un projet de développement de la culture et des semences d'oignons (violet de Galmi) pour limiter la dépendance du pays vis-à-vis des productions nigériennes (David, 1996; David et al., 1998). Le lancement de ces programmes maraîchers répondait à une volonté affichée par les deux états d'assurer l'autosuffisance alimentaire de leurs populations ${ }^{7}$ dans un contexte où les restrictions budgétaires imposées par l'amorce de la chute des cours de l'uranium et du complexe cacao/café les obligeaient à abandonner les projets hydro-agricoles de grande envergure (développement des cultures de riz et de coton) et à se recentrer sur les micro-projets d'irrigation. Les mesures de promotion du maraîchage qui furent développées dans ce cadre ont essentiellement consisté en un travail de vulgarisation: diffusion de nouvelles semences (oignon violet de Galmi au Sénoufo, salade, chou, aubergine, pomme de terre, poivron, carotte, betterave, navet, radis dans le Songhay) et sensibilisation par rapport aux techniques culturales associées via la mise en place de parcelles de démonstration.

16 En prenant son envol à l'issue de la période d'étalement de ces mesures, le développement maraîcher des campagnes songhay et sénoufo semble en être la conséquence directe. C'est du moins ce que suggèrent la plupart des responsables agricoles interrogés lors de nos enquêtes de terrain et certains travaux de recherche (Beaumont \& Borell, 2003, p. 11; Koré Harouna, 1989, p. 1). Produit exclusif d'initiatives prises en dehors de tout consensus local, la diffusion du maraîchage correspondrait ainsi à un phénomène parachuté de l'extérieur. Une telle interprétation pose toutefois problème. En effet, comment comprendre le décalage temporel entre le lancement des politiques de promotion du maraîchage et l'amorce de la diffusion des cultures maraîchères? Pourquoi les paysans n'ont-ils véritablement adopté ces cultures que dans la phase terminale de telles politiques?

17 Ce "temps de réaction" montre que l'impact des mesures de sensibilisation au maraîchage n'a pas été automatique et que ce n'est, en réalité, qu'à partir du moment où les paysans en ont ressenti le véritable besoin qu'ils se sont effectivement tournés vers cette activité ${ }^{8}$. Son adoption serait alors plutôt l'expression d'une dynamique endogène de développement. Pour vérifier cette hypothèse, il convient de reprendre l'analyse du processus de diffusion des cultures maraîchères en y intégrant le paysan lui-même et en se demandant si la généralisation du maraîchage à partir de la fin des années 1980 dans le Songhay et du début des années 1990 dans le Sénoufo ne fait pas écho à d'importantes mutations enregistrées dans le même temps par ces paysanneries. 


\section{La diffusion du maraîchage : une dynamique endogène de développement}

\section{La défaillance des grandes cultures céréalières pluviales}

L'analyse comparée de la démographie et de l'évolution des principales cultures céréalières pluviales des pays songhay et sénoufo au cours des trente dernières années (tableau 1) montre qu'après s'être maintenues à des taux d'accroissement annuel moyen supérieurs ou égaux à ceux de la population (et donc des besoins), les productions de milsorgho et de maïs voient leur croissance s'infléchir au cours des années 1990 et passer sous le niveau du croît démographique9. Il en découle une rupture nette de l'équilibre entre l'accroissement de ces productions et l'accroissement de la population.

Tableau 1. Evolution comparée des principales productions céréalières pluviales et de la population des Pays songhay et sénoufo.

\begin{tabular}{|c|c|c|c|c|c|c|c|c|}
\hline \multirow{2}{*}{ Régions } & & \multicolumn{4}{|c|}{ Effectifs } & \multicolumn{3}{|c|}{$\begin{array}{l}\text { Taux d'accroissement } \\
\text { annuel moyen }\end{array}$} \\
\hline & & 1970 & 1980 & 1990 & 2000 & $70-80$ & $80-90$ & 90-00 \\
\hline \multirow[t]{2}{*}{ Songhay } & $\begin{array}{l}\text { Productions de mil } \\
\& \text { sorgho (en } \\
\text { tonnes }\end{array}$ & 86800 & 109900 & 145500 & 154100 & $+2,4 \%$ & $+2,8 \%$ & $+0,6 \%$ \\
\hline & Population & 297000 & 374000 & 477000 & 612000 & $+2,3 \%$ & $+2,5 \%$ & $+2,5 \%$ \\
\hline \multirow{2}{*}{ Sénoufo } & $\begin{array}{l}\text { Productions de } \\
\text { maïs (en tonnes) }\end{array}$ & 257000 & 349000 & 491000 & 632000 & $+3,1 \%$ & $+3,5 \%$ & $+2,5 \%$ \\
\hline & Population & 586000 & 726000 & 981000 & 1498000 & $+2,2 \%$ & $+3,1 \%$ & $+4,3 \%$ \\
\hline
\end{tabular}

Sources : INS Niger (Enquête Démographique de 1960 et RGPH de 1977, 1988 et 2001), INS Côte d'Ivoire (RGPH de 1965, 1975, 1988 et 1998), Ministère Nigérien de l'Agriculture et FAO.

Conjointe aux deux espaces étudiés, cette rupture y relève toutefois de mécanismes différents. Au Sénoufo, elle apparaît comme étroitement liée à la raréfaction des terres disponibles pour la culture pluviale consécutive d'une croissance démographique soutenue depuis 30 ans (tableau 1) et de la densification des espaces ruraux: de 10 hab./ $\mathrm{km}^{2}$ en 1970 à 25 en 2000 pour les zones de plus faibles densités, mais de 60 à plus de 100 hab. $/ \mathrm{km}^{2}$ pour les campagnes d'occupation ancienne situées entre les villes de Korhogo et Ferkéssédougou (SEDES, 1962-1965). Ces évolutions sont la conséquence de l'effet cumulé de l'accroissement naturel ${ }^{10}$, du mouvement de sédentarisation de pasteurs Peuls (amorcé à la fin des années 1970) et du tarissement de l'émigration vers les chantiers de plantations et les villes de la zone forestière (depuis le milieu des années 1980) (Fromageot, 1996). L'amplification des productions céréalières requise par cet accroissement démographique a pu - dans un premier temps - être supportée par une extension substantielle des superficies cultivées. Celles du maïs sont ainsi passées de 330000 ha en 1970 à 682000 en $1990^{11}$. Mais une telle extension a rapidement débouché 
sur la raréfaction du stock de terres disponibles et sur l'impossibilité de continuer à étendre les cultures de maïs à un rythme soutenu (à peine 700000 ha cultivés en 2000) ${ }^{12}$. Et malgré qu'une pareille réduction des possibilités de défricher ait été partiellement contrebalancée par la hausse des rendements due au détournement des intrants destinés au coton (de $720 \mathrm{~kg} / \mathrm{ha}$ en 1990 à $900 \mathrm{~kg} / \mathrm{ha}$ en 2000), cette hausse ne fut pas suffisante pour permettre un accroissement des productions supérieur à celui de la population (tableau 1). Au Songhay, le décrochage entre la croissance des productions de mil-sorgho et celle de la population est surtout lié à la chute brutale du taux d'accroissement des productions (tableau 1). Cette dernière s'explique par la récente multiplication des irrégularités pluviométriques ${ }^{13}$ qui - dans un contexte de stagnation des itinéraires techniques et malgré une importante extension des superficies cultivées (de +3400 ha au cours des années 1980 à +119000 dans les années 1990) - a engendré une sérieuse baisse du rendement moyen des mil et sorgho (de $498 \mathrm{~kg} / \mathrm{ha}$ en 1990 à $375 \mathrm{~kg} / \mathrm{ha}$ en $2000^{14}$ ).

Qu'elle soit surtout liée à la raréfaction des terres (Sénoufo) ou plutôt à la baisse des rendements (Songhay), la rupture d'équilibre entre l'augmentation des principales productions céréalières et la croissance démographique conduit à un net affaiblissement des stocks de céréales disponibles par exploitation familiale à partir du début des années 1990 et, par voie de conséquence, à une mise en danger de leur subsistance.

\section{La déliquescence de l'encadrement des paysans}

21 Or, ce bouleversement intervient alors que les mesures d'appui aux paysans diminuent. En effet, la baisse continue des cours des matières premières (uranium, cacao et café) combinée aux restrictions budgétaires induites par l'adoption de plans d'ajustement structurel et à la dispersion de l'aide publique au développement $\left(\mathrm{APD}^{15}\right)$ en faveur de nouveaux intermédiaires locaux (ONG) affaiblissent les capacités d'intervention des états dans les années 1990. Les pouvoirs publics sont alors incapables de développer les mesures susceptibles d'apporter une solution ou une alternative au problème de la céréaliculture (reconduction des programmes de promotion du maraîchage engagés au milieu des années 1980 par exemple ou renforcement de l'encadrement des cultures de rente). Et bien que ce désengagement étatique se soit accompagné de l'irruption des ONG sur la scène de l'encadrement en milieu rural, une telle irruption ne s'est pas traduite par un renforcement tangible des appuis aux agricultures songhay et sénoufo. C'est que si les ONG ont pris leur essor dans la réorientation des flux d'APD, le réaménagement parallèle de leur distribution sectorielle en faveur des services ${ }^{16}$ et l'affaiblissement subséquent des crédits destinés au développement agricole ont empêché cet essor de déboucher sur un déploiement significatif des interventions de soutien aux paysans (tableau 2). Dans les années 1990, des projets de développement ont certes vu le jour, mais ils se sont limités à un nombre restreint d'actions micro-spatiales (plantation de nim (Azadirachta Indica) sur la dune de Méhana, aménagement de canaux d'irrigation à Gothey par le FIDA, distribution de vélos aux maraîchers de Korhogo par l'ONG Animation Rurale Korhogo...). 
Tableau 2. Evolution de l'aide publique octroyée aux développements de l'agriculture et des services du Niger et de la Côte d'Ivoire.

\begin{tabular}{|l|l|l|l|l|l|}
\hline \multicolumn{2}{|l|}{$\begin{array}{l}\text { Moyennes quinquennales de l'APD en } \\
\text { valeur constante (million de \$ 2004) selon } \\
\text { le pays et le secteur }\end{array}$} & $\mathbf{1 9 8 0 - 1 9 8 4}$ & $\mathbf{1 9 8 5 - 1 9 8 9}$ & $\mathbf{1 9 9 0 - 1 9 9 4}$ & $\mathbf{1 9 9 5 - 1 9 9 9}$ \\
\hline \multirow{2}{*}{ Niger } & Agriculture \& & 74 & 66 & 49 & 16 \\
\cline { 2 - 7 } & $\begin{array}{l}\text { Services } \\
\text { infrastructures sociales }\end{array}$ & 67 & 70 & 55 & 90 \\
\hline \multirow{2}{*}{ Côte d'Ivoire } & Agriculture \& & 63 & 42 & 44 & 42 \\
\cline { 2 - 7 } & $\begin{array}{l}\text { Services } \\
\text { infrastructures sociales }\end{array}$ & 31 & 11 & 108 & 154 \\
\hline
\end{tabular}

Source : CAD/OCDE

En prenant place dans un contexte de détérioration des mesures exogènes d'assistance à l'agriculture, la défaillance des grandes cultures céréalières pluviales des Songhay et Sénoufo contraint leurs paysans à s'engager dans une recherche systématique de revenus complémentaires au cours des années 1990 (et dès la sécheresse de 1987 pour les Songhay). Or, c'est précisément à ce moment que les cultures maraîchères prennent leur essor. Faut-il donc y lire une réponse des paysans à un état de dépendance chronique visà-vis des stratégies de rente ? Pour répondre à cette question, il convient de vérifier s'il existe une relation de cause à effet entre la recherche systématique de revenus complémentaires et l'adoption du maraîchage.

\section{L'obligation de diversifier les sources de revenus}

Pour faire l'acquisition de revenus, les unités familiales du Songhay et du Sénoufo disposent classiquement d'un ensemble de stratégies rémunératrices individuelles parmi lesquelles l'exode masculin de saison sèche, la pratique de cultures commerciales et la vente de bétail sont les plus répandues. Mais alors que s'accroît la dépendance des cellules familiales vis-à-vis de telles stratégies, ces dernières commencent à montrer des signes d'essoufflement.

L'exode masculin de saison sèche vers les plantations et les grandes villes du golfe de Guinée se heurte ainsi depuis le milieu des années 1980 à un ensemble de complications (dégradation des conditions de vie et de travail dans les mégapoles, crise de l'économie de plantation, xénophobie...) rendant plus aléatoires les chances d'y trouver un revenu (Dubresson \& Raison, 2003 ; Turner, 2000 ; Fromageot, 1996). Et même si ces complications peuvent être en partie résorbées par une modification des pratiques migratoires (prolongement des séjours, diversification des destinations, intensification des mouvements intra-régionaux...), elles plaident néanmoins pour un renforcement des alternatives économiques mobilisables au sein-même du village. Le problème est que les habituelles sources villageoises de revenus sont, elles-aussi, confrontées à un certain épuisement. 

rapport (riz chez les Songha et coton en pays sénoufo) accusent une baisse de rentabilité au cours des années 1990. Le désengagement étatique dans le soutien et l'encadrement de ces productions ainsi que la privatisation des anciennes sociétés d'état (comme la CIDT) en sont les causes principales. C'est qu'en réduisant les capacités d'entretien des périmètres rizicoles, en faisant disparaitre les subsides aux intrants et en grevant les capacités d'achat de ces cultures (fin des subsides aux prix de cession du coton fibre en Côte d'Ivoire, suppression des mesures de protection du marché du riz au Niger), ils contribuent à en affaiblir le caractère rémunérateur tout en favorisant l'alourdissement des coûts de production. Depuis 1995, la baisse de rentabilité du coton sénoufo a par ailleurs été accentuée par la chute des cours mondiaux. La troisième grande source de revenus individuels est le capital bétail. Toutefois, l'affaiblissement prolongé du nombre moyen de têtes de bétail par habitant (de 2,6 au début des années 1980 à moins de 1,6 au cours des années 1990 pour le Songhay ${ }^{17}$ ) suite à la dilapidation des cheptels lors de la crise alimentaire de 1984 et à la trop lente reconstitution de ceux-ci au cours des années 1990 rend le déstockage de ce capital incapable de constituer une solution durable à la baisse de rentabilité des cultures de rapport.

que les difficultés qui touchent les filières d'émigration accentuent la dépendance des exploitations songhay et sénoufo vis-à-vis des sources locales de revenus, la baisse de la rentabilité du riz et du coton ainsi que la difficile mobilisation du capital bétail obligent donc leurs membres à diversifier leurs activités rémunératrices.

\section{Le vivrier marchand : une option stratégique}

Cette obligation de diversification intervient alors que le marché du vivrier est en pleine expansion. La demande locale en produits vivriers n'a jamais cessé de se développer parallèlement à la croissance continue des villes de Niamey et d'Abidjan ${ }^{18}$ ainsi que des foyers urbains secondaires. Elle s'est encore récemment accentuée suite aux restrictions des importations (due à l'impécuniosité des états) et à la dévaluation du franc CFA en 1994 (Dubresson \& Raison, 2003; David \& Moustier, 1998; Chaléard, 1996). Et si les paysans songhay et sénoufo disposent tous d'une série de cultures d'appoints dont l'amplification peut - dans le cadre de cet essor - contribuer à la diversification des revenus, certains d'entre eux ont par ailleurs hérité d'un ensemble d'infrastructures, d'outils ou de pratiques les rendant particulièrement enclins à étayer cette diversification par l'adoption de la culture maraîchère.

\section{Le maraîchage : une activité encouragée par un accès privilégié à l'eau}

La pratique du maraîchage requiert une source en eau pérenne qui soit suffisamment accessible. Ceci afin de satisfaire aux travaux d'arrosage soutenu qu'exige une production de légumes à caractère commercial. Et de ce point de vue, les territoires du Songhay et du Sénoufo disposent d'avantages comparatifs réels: ils ont hérité d'une multitude d'aménagements hydrauliques mis en place à l'époque des grands projets étatiques de développement agricole (de 1960 au milieu des années 1980). Il en va ainsi des 4500 hectares de cuvettes aménagées dans la portion songhay du fleuve Niger pour stimuler la riziculture et des quelques 300 barrages hydro-pastoraux créés par la SODEPRA ${ }^{19}$ dans le nord ivoirien - autour de Korhogo surtout - pour développer l'élevage en sédentarisant 
les communautés de pasteurs descendus des pays sahéliens lors des épisodes de sécheresse des années 1970 et 1980.

Quelle qu'ait été la fonction qui leur fut attribuée lors de leur installation, ces aménagements font des terroirs songhay et sénoufo où ils se concentrent, des espaces remarquables du point de vue de l'abondance des ressources en eaux pérennes et donc des facilités d'accès à cette eau (encore renforcées au Songhay par la présence du fleuve Niger et par l'édification récente de petits barrages le long du Dargol). De telles facilités offrent à leurs paysans la possibilité de pratiquer un arrosage soutenu tout en limitant l'allongement du temps de travail que cet arrosage requiert lorsqu'il est pratiqué par puisage d'eau (comme c'est fréquemment le cas dans les potagers). Ces espaces sont donc particulièrement bien munis pour accueillir le déploiement des cultures de légumes de contre-saison et donc le passage au maraîchage. Celui-ci y constitue dès lors - pour qui est dépositaire d'un accès à la terre ${ }^{20}$ - une bonne alternative à l'obligation de diversifier les sources locales de revenus, fut-ce au prix d'une multiplication des conflits d'usage avec les anciens utilisateurs des zones humides comme les riziculteurs ou les premiers bénéficiaires des petits aménagements hydrauliques prévus par les pouvoirs publics (à l'exemple des éleveurs dans le nord de la Côte d'Ivoire).

\section{Le maraîchage : une activité valorisant les outils et savoirs hérités}

Confortée par l'accès privilégié à l'eau qu'offrent certaines portions du Songhay et du Sénoufo, l'adoption du maraîchage y est encore favorisée par les possibilités de réutiliser un ensemble d'outils et de savoirs hérités. C'est le cas de la manipulation de l'arrosoir et des techniques culturales du violet de Galmi (semis en rangs, pépinières, repiquage, etc.) qui forment un bagage de connaissances acquises par les Sénoufo grâce au programme de vulgarisation de la culture d'oignon et dont on commence à voir l'intérêt avec l'obligation de diversifier les revenus. C'est également celui du système d'irrigation développé par les insulaires du Niger pour la culture traditionnelle de tabac (juxtaposition de carrés de cultures successivement irrigués selon un aiguillage dessiné par un système d'ouverture/ fermeture de petits barrages en mottes de terre ${ }^{21}$ ) qui se montre particulièrement apte à être réutilisé dans le cadre d'une production abondante de légumes. La petite culture potagère classiquement entretenue par les femmes des Songhay et Sénoufo propose quant à elle un stock déjà diversifié de légumes (en particulier en ce qui concerne la gamme des légumes-feuilles) et d'outils (la houe pour la confection des poquets ; le canari et la calebasse pour l'arrosage) dans lequel les maraîchères peuvent puiser certaines de leurs semences ainsi que les instruments nécessaires à la confection des planches ou à l'irrigation. L'engrais peut être prélevé dans les parcs à boeufs ou auprès de l'élevage domestique. Diffusées dans le cadre des programmes de développement des cultures de riz et de coton, les charrettes permettent à leurs possesseurs de disposer de moyens de transport (notamment de l'engrais) et servent à l'évacuation des productions de légumes qui - au contraire du riz et du coton - ne bénéficient pas d'un système de collecte organisé. Les filières de commercialisation sont ainsi très diversifiées en Côte d'Ivoire: des détaillantes locales aux grossistes approvisionnant les marchés d'Abidjan (Fromageot, 2005).

31 Cet ensemble d'outils et de techniques hérités fait de la culture maraîchère une activité que les paysans songhay et sénoufo mobilisent de manière spontanée et sans multiplier les investissements en intrant-capital. 
En permettant la réutilisation d'héritages multiples dans un contexte d'expansion des marchés urbains de consommation, le maraîchage constitue - pour une bonne partie des paysans songhay et sénoufo - une source de revenus tout à la fois rentable et aisément mobilisable. Culture irriguée de saison sèche, le maraîchage offre, de surcroît, la possibilité de se libérer des contraintes (climatiques, d'exiguïté de l'espace ou de saturations de calendrier agricole en saison humide) auxquelles les cultures d'appoint peuvent être localement soumises. De tels atouts en ont fait une option privilégiée au moment où l'essoufflement des cultures de riz et de coton ainsi que des autres postes rémunérateurs classiques (revenus de l'exode et déstckage du capital bétail) obligeait les paysans à diversifier leurs sources locales de revenus pour faire face à la défaillance de la grande céréaliculture pluviale.

\section{Conclusion}

En prenant place à l'issue des programmes gouvernementaux de promotion de la petite irrigation, le développement maraîcher des campagnes songhay et sénoufo semble en être la conséquence directe, venant alors corroborer la thèse afro-pessimiste selon laquelle les paysans africains ne seraient pas capables de développement endogène. Toutefois, le fait que l'émergence du maraîchage n'ait pas directement suivi le lancement de ces programmes et que sa généralisation se soit produite dans un contexte de déliquescence de l'encadrement du secteur agricole montre que la propagation des cultures maraîchères dans les deux espaces étudiés ne correspond que très marginalement à une dynamique parachutée de l'extérieur. La nouvelle spécialisation maraîchère de ces espaces ruraux doit en réalité être lue comme le résultat d'une capacité des paysans à puiser dans leurs héritages techniques lorsque, à partir du début des années 1990 (et dès la sécheresse de 1987 pour le Songhay), il leur a fallu diversifier leurs sources locales de revenus pour faire face aux défaillances enregistrées par leur système d'activité respectif. Le développement maraîcher des campagnes songhay et sénoufo est donc, avant toute chose, l'expression de l'aptitude de leurs populations à réagir au contexte de crise actuelle, illustrant ainsi les réelles dynamiques des paysanneries africaines et leurs capacités à prendre en charge la construction de leur avenir.

\section{BIBLIOGRAPHIE}

AGENCE FRANÇAISE DE DEVELOPPEMENT (2005), L'aide au développement : évolutions récentes et grands débats, Paris.

ANADER (1996), Résultats du projet Oignon PNUD-FAO. Occupons-nous de nos Oignons, Côte-d'Ivoire.

AUTISSIER V. (1994), Jardins des villes, jardins des champs. Maraîchage en Afrique de l'Ouest, $d u$ diagnostic à l'intervention, Coll. Le point sur, Ed. du GRET.

BEAUCHEMIN C. (2000), Le temps du retour? L'émigration urbaine en Côte-d'Ivoire, une étude géographique, Thèse nouveau régime, Université Paris 8. 
BEAUMONT E. \& BORRELL T. (2003), Caractérisation et cartographie du maraîchage intra- et périurbain dans la Communauté Urbaine de Niamey ; besoins spécifiques en information, rapport de stage, Centre Régional Agrhymet.

BENSAAD A. (2002), “La grande migration africaines à travers le Sahara”, Méditerranée, 3-4, pp. 41-52.

BERNUS E. \& SIDIKOU A.H. (1980), Atlas du Niger, Les Atlas Jeune Afrique, Paris, Editions Jeune Afrique.

CECCHI P. (1998), “De la construction d'un objet pluridisciplinaire : les "Petits Barrages" du Nord de la Côte-d'Ivoire", NSS 6, 2, pp. 73-83.

CHALEARD J.-L. (1996), Temps des villes, Temps des vivres. L'essor du vivrier marchand en Côte-d'Ivoire, coll. Hommes et Sociétés, Karthala.

CHRETIEN J.-P. et al. (2005), "Misères de l'afro-pessimisme", Afrique et Histoire, 3, pp. 183-211.

COELO S. et al. (1997), Etude "Diagnostic et stratégie de sécurité alimentaire pour le Niger", Rapport Final, Institut de Recherches et d'Applications des Méthodes de Développement.

COLOMB E. \& BOUMAZA N. (1994), "Le secteur informel, une ressource : l'exemple des fondeurs de marmites du marché de Katako (Niamey)”, Revue de géographie alpine, Numéro hors-série, 1, pp. 259-277.

COQUERY-VIDROVITCH C. (1997), "L'Afro-pessimisme au seuil du troisième millénaire”, Clio en Afrique, 3, http://www.up.univ-mrs.fr/wclio-af/numero/3/editorial/index.html.

COURADE G. (dir.) (2006), L'Afrique des idées reçues, Coll. Mappemonde, Belin.

DAVID O. (1996), “L'oignon du Niger dominera-t-il longtemps les marchés d'Abidjan ?”, Grain de sel, 3, Bulletin Inter-Réseaux, Paris, pp. 10-11.

DAVID O. \& MOUSTIER P. (1998), "Lorsque le gros maigrit, le maigre meurt : l'organisation du commerce de l'oignon en Afrique de l'Ouest”, in EGG J. \& HERRERA J. (eds.), Echanges transfrontaliers et intégration régionale en Afrique subsaharienne, Revue Autrepart, 6, pp. 105-122.

DUBRESSON A. \& RAISON J.-P. (2003), L'Afrique subsaharienne. Une géographie du changement, Paris, Armand Colin.

FROMAGEOT A. (1996), Etude de petits périmètres maraîchers dans un village du nord de la Côte-d'Ivoire, Mémoire de Maîtrise de Géographie, Université Paris 10 Nanterre.

FROMAGEOT A. (2003), Vallées maraîchères, Economies vivrières, Mémoire de Doctorat de géographie, Université Paris 1, 3 volumes.

FROMAGEOT A. (2005), "Dépasser l'enclavement : le maraîchage des savanes et l'approvisionnement d'Abidjan”, Espace, Population, Sociétés, 1, pp. 83-98.

FROMAGEOT A. (2007), "L'essor du maraîchage marchand et les petits barrages dans le nord de la Côte d'Ivoire", in CECCHI P. (éd.), De Terre et d'Eau. Les petits barrages du nord de la Côte d'Ivoire, Coll. Latitudes 23, IRD Editions, Paris, 20 p. (sous presse).

GOSSELAIN O. \& BASTIN S. (2005), “Famine, routine et journalisme”, Hémisphères, 31, pp. 6-7.

GREGOIRE E. (1998), “Sahara nigérien : terre d'échanges”, Autrepart, 6, pp. 91-104.

GUENGANT J.-P. \& BANOIN M. (2002), Dynamique des populations, disponibilités en terres et adaptation des régimes fonciers : le cas du Niger, FAO-CICRED.

HAROUNA K. (1989), Etude de la filière maraîchage au Niger. 
MINISTERE DU PLAN (1969), Etude de la commercialisation des produits maraîchers locaux sur les marchés d'Abidjan, juin, République de Côte-d'Ivoire.

MYERS G.A. (2001), "Introductory human geography textbook representations of Africa”, Professional Geographer, 53, 4, pp. 522-532.

NAUDET J.-D. (1999), Trouver des problèmes aux solutions. Vingt ans d'aide au Sahel, Club du Sahel, OCDE.

OLIVIER DE SARDAN J.-P. (1969), Système des relations économiques et sociales chez les Wogo (Niger), Paris, Institut d'ethnologie.

OLIVIER DE SARDAN J.-P. (1984), Les sociétés songhay-zarma (Niger-Mali) : chefs, guerriers, esclaves, paysans, Paris, Karthala.

PIVETEAU A. (1994), ONG et développement agricole au Burkina Faso. Présence majeure et effets mineurs, ORSTOM, Ouagadougou, Document de travail $n^{\circ}$ 6, Programme de recherche Politiques et développement agricoles et agro-industriels au Burkina Faso.

PLIEZ O. (2002), "Vieux réseaux et nouvelles circulations entre les deux rives du Sahara", Méditerranée, 3-4, pp. 31-40.

POURTIER R. (2003), “Les savanes entre local et global : milieux, sociétés, espaces”, Cahiers Agricultures, 12, 4, pp. 213-218.

RAISON J.-P. (1993), “Les formes spatiales de l'incertitude en Afrique contemporaine”, Travaux de l'Institut de Géographie de Reims, numéro spécial Espaces africains en crise : formes d'adaptation et de réorganisation, 83-84, pp. 5-18.

RAYNAUT C. et al. (dir.) (1997), Sahels. Diversité et dynamiques des relations sociétés-nature, Paris, Editions Karthala.

ROUCH J. (1997), Les hommes et les dieux du fleuve : essai ethnographique sur les populations songhay du Moyen Niger, 1941-1983, Paris, Artcom.

SALIFOU A. (2003), Le Niger, Paris, L'Harmattan.

SEDES (1962-1965), Région de Korhogo : étude de développement socio-économique, Ministère des Finances, des Affaires sociales et du Plan, Abidjan, 9 volumes (Vol. 2 : Rapport sociologique, 101 p. ; vol. 3 : Rapport agricole, 264 p. ; vol. 9 : Rapport de synthèse, 52 p.).

SERGENT H. (1996), "Les mutations des systèmes de production dans trois villages de la vallée du Niger : des adaptations rapides pour des changements lents", Actes du colloque SPP/E tenu à Niamey du 14 au 15 décembre 1995. Thème : agricultures en mutation, Annales de l'Université Abdou Moumouni de Niamey, Numéro hors-série, Niamey, pp. 193-212.

SMITH S. (2003), Négrologie. Pourquoi l'Afrique meurt, Calmann-Lévy.

TURNER M.D. (2000), "Drought, domestic budgeting and wealth distribution in Sahelian households", Development and Change, 31, pp. 1009-1035.

ZOUNGRANA T.P. (1998), “Enclavement et développement des cultures irriguées au BurkinaFaso", Aspects du Développement économique dans un pays enclavé : Le Burkina-Faso, CRET, Collection "Pays enclavés", 9, pp. 25-48.

\section{NOTES}

1. Voir Chrétien J.-P. et al., 2005. 
2. Les boeufs sont également utilisés comme attelage sur les aménagements rizicoles du Niger ainsi que dans le cadre de la culture cotonnière du Sénoufo.

3. Rapports annuels des statistiques de la campagne de contre-saison pour le département de Niamey (1984-1987) et de Tillabéry - Communauté Urbaine de Niamey y compris (1994-2001).

4. CIDV : Compagnie ivoirienne de développement des produits vivriers.

5. ANADER : Agence nationale d'appui au développement rural.

6. Départements d'Odienné, Tengrela, Boundiali, Korhogo et Ferkessédougou.

7. Dans le cas ivoirien, il s'agissait essentiellement de réduire la dépendance d'Abidjan par rapport aux importations d'oignons depuis l'étranger.

8. En sachant qu'une comptabilisation précise des productions et producteurs de légumes se met en place dès le lancement des politiques de promotion des cultures maraîchères, ce décalage ne peut être imputé à des problèmes de sous-enregistrement.

9. La population du Songhay est celle des départements de Téra et Tillabéry, tandis que la population du Sénoufo correspond aux effectifs additionnés des départements d'Odienné, Tengrela, Boundiali, Korhogo et Ferkessédougou. Tels que repris dans le tableau 1, les chiffres de population correspondent à des moyennes quinquennales centrées sur la date reprise dans le tableau et calculées sur base d'effectifs annuels estimés par les taux d'accroissement annuel moyen intercensitaires (1960, 1977, 1988 et 2001 pour le Songhay ; 1965, 1975, 1988 et 1998 pour le Sénoufo). Les quantités produites correspondent aux moyennes quinquennales (centrées sur la date reprise dans le tableau) des productions enregistrées pour les départements de Téra et Tillabéry (Songhay) et, pour le niveau national dans le cas du maïs, Sénoufo (valeur approchée).

10. Au niveau national, le taux d'accroissement naturel de la population est passé de $2,5 \%$ par an dans les années 70 à 3,7 \% dans les années 90 (RGPH de 1965, 1975, 1988 et 1998).

11. Statistiques Agricoles de la FAO.

12. D'autant que la culture de coton était alors en pleine expansion.

13. Les statistiques pluviométriques publiées par la Direction de la Météorologie Nationale du Niger pour la station de Tillabéry montrent une tendance à la multiplication des péjorations pluviométriques (déficits ainsi que variabilités inter-annuelles et inter-mensuelles des précipitations) depuis le début des années 1980.

14. Ministère de l'Agriculture.

15. L'APD est la principale source externe de financement dans les pays du Sahel (AFD, 2005).

16. Ajustements, traitements de la dette, appui à la gestion et services sociaux.

17. Direction de l'élevage.

18. Au cours des années $1990:+3 \%$ par an pour Abidjan et $+4,1 \%$ pour Niamey.

19. SODEPRA : Société pour le Développement de la Production Animale. Fusionne en 1993 avec la CIDV au sein de l'ANADER en Côte d'Ivoire.

20. Et gestionnaire d'une partie de la main- d'oeuvre familiale dans le cas sénoufo.

21. Voir notamment J.-P. Olivier de Sardan, 1969.

\section{RÉSUMÉS}

En prenant place à l'issue des programmes de promotion de la petite irrigation qui furent initiés au début des années 1980 par les gouvernements nigérien et ivoirien, le développement maraîcher des campagnes songhay et sénoufo semble en être la conséquence directe. Ce qui 
corroborerait la thèse afro-pessimiste selon laquelle les paysans africains ne seraient plus capables de développement endogène. Toutefois, le fait que l'émergence du maraîchage ait accusé un certain retard par rapport au lancement de ces programmes et que sa généralisation se soit produite dans un contexte d'affaiblissement des encadrements du secteur agricole montre que la propagation des cultures maraîchères dans ces deux espaces ne correspond que très marginalement à une dynamique exogène de développement. Cette propagation doit en réalité être lue comme le résultat d'une capacité des paysans à puiser dans leurs héritages techniques lorsque, à partir du début des années 1990, il leur a fallu diversifier leurs sources locales de revenus pour faire face aux défaillances enregistrées par leur système d'activité respectif.

By appearing at the end of the small-irrigation development programs wich were initiated at the beginning of the 80 s by the governments of Niger and Ivory Coast, the expansion of market gardening in the Songhay and Senufo areas seems to have been directly induced by them. Which would confirm the afro-pessimist conviction that the african farmers are no more able to take part in their own development. However, the facts that the emergence of market gardening hasn't closely followed the launchning of such programs and that its diffusion has occurred in contexts of decreasing investments to the agricultural sector tend to show that the development process of this new type of commercial agriculture doesn't correspond to an exogenous dynamic. In fact, this development must be seen as a result of farmers' ability to mobilize their technical inheritances when - at the beginning of the 90 s - they became obliged to diversify their villagebased income sources to answer the structural crisis encountered by the main food-producing and commercial agricultures.

\section{INDEX}

Mots-clés : diffusion, maraîchage, culture maraîchère, développement endogène, milieu rural, système d'activité, programme/projet de développement, intervention de l'état, ONG, riz, coton, héritage technique, campagne sahélo-soudanienne, Niger, Côte d'Ivoire, Songhay, Sénoufo

Keywords : diffusion, market gardening, endogenous development, local initiative, rural area, activity system, programme/project of development, NGO, rice, cotton, technical inheritance, hydraulic infrastructure, Sahelo-Sudanian area, Niger, Ivory Coast, Songhay, Senufo

\section{AUTEURS}

\section{STÉPHANE BASTIN}

Laboratoire de Géographie humaine de l'Université Libre de Bruxelles, sbastin@ulb.ac.be

\section{AUDREY FROMAGEOT}

UMR Métafort, EEA-CEMAGREF, audrey.fromageot@clermont.cemagref.fr 